\title{
Procedimentos clínicos com impactos positivos no bem-estar de bovinos leiteiros
}

Wilmar Sachetin Marçal', Murilo Rezende Figueira

Universidade Estadual de Londrina (UEL), Londrina, PR, Brasil

*Autor correspondente

e-mail:wilmar@uel.br

\section{Resumo}

Nos atendimentos clínicos realizados por docentes da Universidade Estadual de Londrina em fazendas, sempre existiram bovinos enfermos, necessitando de tratamento clínico. Assim, desde 2012, os procedimentos são executados com critérios de manejo racional, com técnicas e medicações de reduzido impacto ao bemestar, evitando-se estresse e acidentes. Dois tratamentos tornaram-se rotineiros nessa prática, permitindo aprimoramento aos alunos interessados na Buiatria. 0 primeiro refere-se ao combate aos parasitas, utilizando-se versões modernas tipo pour on contra carrapatos, bernes, vermes e moscas. A aplicação do produto foi realizada com abordagem pelo lado esquerdo dos bovinos, com distribuição uniforme do líquido. 0 outro procedimento refere-se à fluidoterapia de suporte por via intraperitoneal. Tanto a aplicação com produtos pour on, quanto a infusão intraperitoneal foram realizadas em 286 vacas de 12 propriedades rurais, raça Girolando, idade entre 32 e 54 meses de vida e peso médio de $420 \mathrm{~kg}$. Os bovinos apresentavam ectoparasitas e diferentes quadros clínicos possibilitando infusão com soluções cristaloides (2 a 5 litros), acrescidas de complexos vitamínicos B1 e B12 (40 mL), hepatoprotetores (200 mL), borogluconato de cálcio $(250 \mathrm{~mL})$, glicose a $50 \%(100 \mathrm{~mL})$ e iodeto de sódio $(40 \mathrm{~mL}) .0$ acesso intraperitoneal foi feito pela fossa paralombar direita, utilizando-se agulhas 40x16 mm com equipo acoplado, após antissepsia com álcool 70\%. Para ambos os procedimentos a contenção foi realizada sem necessidade de instrumentos traumáticos. A aplicação pour on era realizada, no máximo, em 10 segundos. Na infusão por via intraperitoneal, o tempo médio gasto para cada $1.000 \mathrm{~mL}$ de solução foi de 21 minutos, sem intercorrências cardiopulmonares, nem abscessos, miíases e peritonites. Em pesquisas anteriores percebeu-se que a distribuição do produto pour on ocorria pela linha lombar dos animais, com perdas significativas por assimetria no despejo, falta de habilidade do aplicador e/ou por influência do vento. Havia "varredura" do produto pela própria cauda do bovino, retirando o mesmo da linha lombar e retendo parte líquida na "vassoura da cauda". Percebeu-se 
também que as vacas lambiam o produto tóxico facilmente. Por isso, a aplicação foi padronizada, abordando os animais pelo lado esquerdo, fluindo o produto da esquerda para a direita, obedecendo a "naturalidade grafológica", com o medicamento aplicado da nuca até a "linha da cruz", já que a absorção é percutânea. Isso permitiu distribuição uniforme pelo aproveitamento da função motora de cada indivíduo aplicador, seja ele destro ou sinistro. Nas infusões intraperitoneais, as inoculações eram atraumáticas, com ganho de tempo nos procedimentos. Sabe-se que as injeções na veia jugular do bovino, por exemplo, podem causar flebites, alterações comportamentais e acidentes. Nos procedimentos houve pouca necessidade de contenção física dos bovinos, redução do tempo de manipulação dos medicamentos, mínima oportunidade de reações de fuga do animal, administrações atraumáticas e otimização do tempo na rotina das fazendas. 